\title{
Usos y apropiaciones del patrimonio urbano VS identidad perdida o conservada
}

\begin{abstract}
Mabel Teresa Chaos Yeras ${ }^{1}$
Resumen: En la configuración de una ciudad influyen diversos factores como el medio geográfico, la población y el marco histórico específico. Unido a ello, se establecen relaciones funcionales y se produce un proceso de apropiación y usos del espacio urbano. Ello ayuda a reforzar la imagen de la ciudad que refleja su propia historia, valor, carácter y personalidad. De allí que la identidad cultural no exista sin la memoria, sin la capacidad de reconocer el pasado, sin elementos o referentes que le son propios y que permiten construir el futuro. Las prácticas contemporáneas en determinadas áreas geográficas hacen coincidir el espacio físico, social y turístico, donde se generan grandes tensiones entre la memoria y el olvido, entre la identidad perdida o conservada. Sin embargo, las soluciones son posibles siempre que se alcance el equilibrio entre, la satisfacción de las necesidades del presente y la preservación de la significación cultural del patrimonio.
\end{abstract}

Palabras-clave: identidad cultural, turismo urbano; conservación del patrimonio

\section{Usos e apropriações de patrimônio urbano VS identidade perdida ou conservada}

Resumo: Na configuração de uma cidade, vários fatores influenciam, como o ambiente geográfico, a população e o quadro histórico específico. Juntamente com isso, as relações funcionais são estabelecidas e um processo de apropriação e uso do espaço urbano é produzido. Isso ajuda a reforçar a imagem da cidade que reflete sua própria história, valor, caráter e personalidade. Portanto, a identidade cultural não existe sem memória, sem a capacidade de reconhecer o passado, sem elementos ou referentes que sejam próprios e que permitam construir o futuro. As práticas contemporâneas em certas áreas geográficas fazem coincidir o espaço físico, social e turístico, onde grandes tensões são criadas entre memória e esquecimento, entre identidade perdida ou preservada. Contudo, soluções são possíveis desde que se alcance o equilíbrio entre satisfazer as necessidades do presente e preservar o significado cultural do patrimônio..

Palavras-chave: identidade cultural; turismo urbano; conservação do patrimônio

\section{Uses and appropriations of urban heritage VS lost or conserved identity}

Abstract: In the configuration of a city there are various influencing factors such as the geographic environment, the population and the specific historical framework. Together with this, functional relationships are established and a process of appropriation and use of the urban spaces is produced. This helps to reinforce the image of the city that reflects its own history, value, character and personality. Hence, cultural identity does not exist without memory, without the ability to recognize the past, without elements or referents that are its own and that allow building the future. Contemporary practices in certain geographical areas make the physical, social and tourist space coincide, where great tensions are created between memory and forgetting, between lost or preserved identity. However, solutions are possible as long as the balance is reached between satisfying the needs of the present and preserving the cultural significance of heritage.

Keywords: cultural identity; urban tourism; heritage conservation

Recebido: janeiro de 2018. Aceite: março de 2018.

${ }^{1}$ Doctora por la Universidad de Sevilla, España (2005), título homologado a Doctora en Ciencias Técnicas en Cuba, y Profesora Titular de la Universidad de Camagüey, Cuba. Email: mabeltchaos@yahoo.com.mx. 


\section{Introducción}

El estudio de la problemática urbana debe considerar una perspectiva de análisis que evite reducir la arquitectura a símbolos carentes de contenido, de forma que la historia pueda ser mucho más cierta para los hombres. Se reconoce que no importa el espacio ni el tiempo, porque la arquitectura tiene un contenido ideológico y la historia puede leerse en la piedra. De esta forma el proceso de configuración de una ciudad se basa en las relaciones funcionales principales, en las que influye el medio geográfico, la población y el marco histórico específico que abarca factores sociales, económicos, políticos e ideológico culturales (Yeras, 2005). A ello se añade que los usos del espacio urbano ayudan a reforzar la imagen de una ciudad, así esta queda establecida a través de los símbolos concretos y las acciones simbólicas que son reconocidos por sus habitantes.

Como plantea Stevens (1998) hay una base social en el proceso de creación de una ciudad en el que influye el entorno social y las estructuras donde se reconoce. Mediante ese proceso de creación los hombres "inscriben" sus obras en las piedras de la ciudad, y aunque ello puede parecer sólo una acción simbólica, se está ante un proceso material y social. En este sentido, Stevens ha planteado que en el proceso de creación de la sociedad se producen los símbolos que permiten mantener el orden social vigente y que estos símbolos forman parte importante de la cultura material que a su vez crea, legitima y reproduce la estructura social. El proceso de creación de la sociedad otorga a la arquitectura una alta carga ideológica, como consecuencia de ello los vínculos entre la arquitectura y la ideología cambian según el contexto espacio-temporal.

El derecho a la ciudad se debatió por años en la distribución del espacio físico según las exigencias de cada momento, en la fragmentación del espacio para dar paso al intercambio y finalmente en la capacidad técnica y científica de la producción del espacio social para satisfacer todas las necesidades, funciones y objetivos sociales. No caben dudas que las creaciones que se materializan en el espacio urbano, en los momentos histórico concretos de la vida del hombre, hoy han alcanzado una connotación global, que pone en peligro la diversidad cultural y la esencia misma de la cultura (Moya \& Brito, 2001).

Unido a lo anterior, la creciente internacionalización de los procesos económicos y tecnológicos, induce a la uniformidad, la imitación y la destrucción de las culturas nacionales. Este fenómeno se expresa en las ciudades con la importación de modelos urbanos y arquitectónicos, la introducción de tecnologías no apropiadas al contexto local, la pérdida del espacio urbano y la destrucción del patrimonio heredado que se concentra mayoritariamente en los centros históricos de las ciudades. Como se ha planteado Yeras (2016, p. 64):

\begin{abstract}
La arquitectura de este tiempo se ha apartado de sus raíces olvidando aspectos tan sensibles como la adaptación al medio, el régimen de brisas, la trayectoria solar y los materiales y técnicas locales; todo lo cual se traduce en ocasiones en un problema más, el encarecimiento de las obras por costos de importación, consumo de energías no renovables y otros muy relacionados con el ciclo de vida de los edificios. La tecnología mal entendida que ha deslumbrado al mundo es en gran medida la responsable del olvido de nuestros orígenes. Se ha obviado la relación del hombre con la naturaleza, se ha creado una enorme confusión como resultado de la gran cantidad de materiales y sistemas constructivos, industrializados, de tal forma que lamentablemente la edificación ahora no identifica al hombre con su medio.

El inicio del siglo XXI marcado por la especulación y los criterios comerciales han creado una arquitectura anónima de gran uniformidad constructiva, carente de elementos capaces de ambientar y hacer más agradable la vida, de tal forma que se han destruido los hábitos de vecindad y comunicación espontánea entre los hombres, con lo que también se ha afectado significativamente el orden social. Muchas construcciones contemporáneas aislan al hombre de su medio, no solo natural sino social, afectando las prácticas cotidianas de intercambio y generando barreras que se ven reflejadas ya no solo en la estructura física de las ciudades, sino también en la estructura de la sociedad.
\end{abstract}

En este sentido, ha sido reconocido que el nivel de autorrealización de un individuo a lo largo de su vida depende críticamente de la calidad del entorno en que se desenvuelve (Boisier, 1999); se establece así, una relación entre medio físico y desarrollo humano personal, que está condicionado por la satisfacción de sus necesidades materiales y espirituales expresadas en estilos de vida asumidos desde la posición que ocupa el individuo en la sociedad. Es aquí donde se reconocen como idóneos los estilos de vida que favorecen al hombre desde su satisfacción espiritual y no sólo desde cuánto posee en la escala material (Castro, 2001); o sea una calidad de vida sustentada en la cultura. Ello es una condición indispensable para la viabilidad a largo plazo de los sistemas económicos, cuyos beneficios pueden contribuir al mejoramiento de la habitabilidad de los núcleos urbanos, es decir, a la existencia de equipamientos básicos, acceso fácil a los servicios públicos y otras actividades, regulaciones en el uso de suelo, 
recuperación de las centralidades, entornos urbanos seguros y saludables, disminución de la violencia, gobernabilidad, participación y gestión (Rueda \& Naredo, 1996).

Las ciudades poseen su propia historia, valor, carácter y personalidad, al decir de Chateloin (2009), constituyen un gran laboratorio cultural, son la evidencia de la evolución de los complejos arquitectónicos y urbanos y de cómo se determinan en ellos los procesos socioculturales y técnicos que las crean, conservan y transforman, de allí que las áreas urbanas históricas resulten elementos fundamentales de la identidad e importantes piezas del patrimonio cultural. La identidad cultural no existe sin la memoria, sin la capacidad de reconocer el pasado, sin elementos simbólicos o referentes que le son propios y que ayudan a construir el futuro. La identidad al decir de Eduardo Galeano $(1975$, p. 57) es "como una mariposa que huye (...) la identidad es cambiante, contradictoria; la identidad fija solo sirve para llenar de objetos los museos...", de allí su carácter dialéctico.

Sin embargo, la globalización neoliberal está fungiendo como elemento aniquilador de las identidades desde el punto de vista cultural. La identidad cultural se basa en una norma de pertenencia, consciente, fundada sobre posiciones simbólicas socialmente construidas, de acuerdo a una cultura particular, con determinados atributos como patrones de vida, religión, lenguaje, etcétera (Pupo, 2007). En general, el concepto de identidad es multidimensional ya que está relacionado con diversas direcciones de análisis de la realidad social, material, estructural y espiritual.

García y Baeza (2004, p. 46), plantean que la identidad cultural debe ser asumida como: "una forma consciente de expresar las concepciones a través del tiempo y es por eso que se concibe como una configuración fenomenológica de los sujetos y grupos humanos en su devenir, es autoconciencia, el mundo de significados y sentidos, proyectos o propuestas, condiciones y situación real de estos con su proyecto en el andamiaje total del espacio sociocultural y la fuerza social que representa. Es el resultado de la configuración y reconfiguración del espacio sin exclusión".

De allí que pueda afirmarse que la identidad sólo es posible y puede manifestarse a partir del patrimonio cultural, que existe de antemano y su existencia es independiente de su reconocimiento o valoración. El patrimonio cultural refleja la vida de la comunidad, su historia e identidad. Su preservación ayuda a reconstruir comunidades desmembradas, a restablecer su identidad, a crear un vínculo con su pasado y a crear un vínculo entre el pasado, el presente y el futuro. El patrimonio y la identidad cultural no son elementos estáticos, sino entidades sujetas a permanentes cambios, están condicionadas por factores externos y por la continua retroalimentación entre ambos.

Desde esta perspectiva, el concepto de identidad cultural hace referencia a hechos culturales y de conciencia; debe ser declarada a partir de su expresión de la vida cotidiana del pueblo y de sus expresiones más concretas: el lenguaje, las instituciones sociales, la cultura popular, el arte, la literatura y la arquitectura las cuales cambian en función del tiempo, el momento histórico y las interpretaciones que coexisten en el marco de las relaciones inter generacionales. El patrimonio cultural cuenta como uno de sus elementos fundamentales con el patrimonio arquitectónico, irremplazable expresión de la riqueza y diversidad de cultura de un pueblo.

Cada comunidad o grupo implicado en la conservación de su patrimonio, es responsable de su gestión, es por ello que las estrategias encaminadas hacia este fin, deben considerar una adecuación respetuosa para nuevos usos, como puede ser el turístico. Sin embargo la relación patrimonio y turismo puede implicar valoraciones encontradas, por lo que es necesario evitar los efectos negativos que puede producir la contaminación, la congestión del tráfico o la banalización social, económica y cultural de la comunidad de acogida, entre otras (Brandis \& Del Rio, 1998). En la última década turismo e identidad cultural, son conceptos que se han manejado con intensidad. El turismo aparece como un medio efectivo para la promoción social del patrimonio. El crecimiento mundial del turismo, incide considerablemente en el ámbito de la cultura y el patrimonio, fundamentalmente a nivel urbano. La puesta en valor de los sitios urbanos en función del turismo, vendría a conformar una de sus modalidades el turismo urbano, segmento turístico con una de las mayores tasas de crecimiento en el barómetro mundial (Yeras \& Sóñora, 2013).

La gestión del patrimonio es el conjunto de medidas que emanan de una planificación para garantizar la conservación y el uso público de los bienes patrimoniales, de allí la necesidad de encontrar los usos más adecuados. En otras palabras según afirma Van Hooff (2006) en el mundo actual, una gestión novedosa del patrimonio, de la diversidad cultural y de la creatividad de las sociedades, puede convertirse en verdadero generador de desarrollo humano, social y económico y en uno de los insumos más sustentables para la cultura y el patrimonio.

En este sentido adquiere importancia vital la 
preservación de la memoria de los pueblos, pese a que en la actualidad se quiera desde el poder, a partir de determinados intereses políticos $y$ económicos, ver la otra cara de la memoria, el olvido. La conservación del patrimonio arquitectónico no tiene sentido si sus valores no son asumidos por la comunidad que es la responsable de su custodia y es la depositaria del mismo (Cárdenas, 1998) pues una ciudad necesita de su memoria para permanecer en el tiempo y salvarse.

\section{Espacio social: de lo geográfico, a lo urbano}

La concepción social del espacio lleva implícito un cambio en el entendimiento del medio natural. Según Varcácel (2000, p. 547) "se trata de entender el espacio no como una especie de contenedor sino como el resultado del proceso de transformación de la naturaleza por el trabajo social, y que esa naturaleza actual no es sino el espacio heredado de generaciones y generaciones que ejercieron ese proceso de transformación durante siglos y milenios". Lo relativo al medio geográfico tiene sus antecedentes en la escuela francesa y más tarde también en la española, donde las investigaciones históricas contaron entre sus líneas de análisis con una vertiente geohistórica. Esto no ha sido casual, "toda sociedad concreta se asienta en un espacio físico determinado que ofrece la naturaleza" (Moro, 1985, p. 207). El medio geográfico es la base de la existencia material del hombre, y este, lo ha utilizado a lo largo de cada una de las fases de desarrollo por las que ha transitado. De lo anterior resulta el papel del hombre como transformador de ese medio, en busca de mejores condiciones para su existencia.

$\mathrm{Al}$ analizar la estructura espacial de cualquier ciudad puede verse reflejado, como plantea Luís Racionero (1986), primeramente un proceso de selección espacial, atendiendo a las actividades predominantes; y en segundo lugar, uno de selección temporal, donde los factores históricoeconómicos, favorecen su crecimiento o estancamiento. Muntañola (2000) reconoce que las tres dimensiones de la arquitectura: proyecto (mente), construcción (arquitectura, ciudad) y uso (sociedad, historia, cultura) son campos de investigación importantísimos, y el núcleo de la investigación arquitectónica es justamente la forma en que el proyecto, el construir y el uso social se relacionan entre sí.

Algunos autores como Bourdieu (1993, como citado en Habas \& Santamaría, 2001), han manejado las relaciones entre las estructuras del espacio físico -urbano- y las del espacio social. Para él, el espacio físico funciona como simbolización espontánea del espacio social. En una sociedad jerárquica, enfatiza, no hay espacio que no esté jerarquizado y, por tanto, que no exprese las jerarquías sociales. En el espacio físico aparecen inscritas las estructuras del espacio social y esa es la razón fundamental por la que se convierten en los lugares donde se organiza y se ejerce el poder de forma sutil o enmascarada a través de los espacios arquitectónicos y urbanos. Es lo que Bourdieu ha dado en llamar "efectos de lugar". Ello permite analizar la construcción de la ciudad como una estructura espacial, morfológica que no puede ser reducida a un simple esquema formal-funcional, pues ella es el producto de un entorno social. Según Bourdieu, la relación del hombre con el espacio no es solamente visual-perceptual, ni estética, ni semiológica, aunque en la práctica el hombre se apropie de signos urbanos, sino que también a través de su uso, de sus actividades, el hombre es capaz de cualificarlo, socializarlo.

La antropología urbana permite un sistémico e integral entendimiento de la ciudad y de las comunidades en general, pues va más allá de una simple descripción de los comportamientos que se dan en ella. Permite reconstruir la lógica de sus pobladores desde ellos mismos, registrando costumbres, concepciones y la interpretación que estos hacen de sus propios actos y su vida; asimismo, las soluciones que los habitantes de la urbe dan o pueden dar a los problemas que esta les impone. La misma tiene dos dimensiones operativas: la dimensión diacrónica y la sincrónica contemporánea (Couceiro, 2009). La dimensión sincrónica contemporánea permite el estudio de tres componentes fundamentales: la dinámica poblacional comunitaria actual; la problemática de identidad en las comunidades y los espacios urbanos. Para Henri Lefebvre (1972), lo urbano no se limita a la morfología urbana; sino que se trata de algo mucho más complejo que es la manera de vivir una sociedad a partir de la base económica, social y cultural. Dicho en otras palabras el espacio social urbano es sede de prácticas sociales y culturales que propician la interacción de los individuos.

Se puede decir que el hombre se desenvuelve siempre en un medio que generalmente ha sido conformado artificialmente por él y, en consecuencia, existe una relación entre el hombre y el espacio que éste crea. En este sentido resulta vital lo que Guanche (1999) ha llamado cultura material y espiritual de los hombres para definir sus valores e intereses, sus aspiraciones 
y necesidades, sus tradiciones y hábitos y sus modos y formas de vida; los que indudablemente repercuten en la estructura física. Por último, cuando se hace referencia al marco histórico específico se considera que los factores económicos condicionan el impulso, el estancamiento o el decaimiento de los asentamientos; de allí la importancia que el poder económico tiene en dicho análisis, mientras que los restantes actúan como reguladores de los recursos económicos. En tal sentido, el marco histórico concreto actúa sobre la estructura física de las ciudades y, por tanto, estas están condicionadas, forman parte y a la vez reflejan dicho marco histórico.

La historia ha demostrado que las relaciones que se dan en un espacio originan una forma determinada y concreta. Es por ello que en la morfología urbana intervienen diversos factores socio-urbanísticos como las características históricas y geográficas, las relaciones establecidas entre centro y periferia, la valorización y desvalorización simbólica del sitio por los hombres que lo habitan y las imágenes de las que se apropian. En este sentido es válido utilizar como método la reinterpretación de la estructura de la ciudad, pues ello permite comprobar la llamada eficacia socializadora de la morfología urbana.

La ciudad y su arquitectura están sometidas a un uso dinámico, donde muchas veces con el transcurso del tiempo, la ciudad debe ser capaz de asimilar los cambios que impone la sociedad en continuo desarrollo. En este sentido, la arquitectura no debe ser considerada como un objeto, sino como la materialización de una relación social, pues su historia no es la historia de los edificios, sino la de las aspiraciones y los vínculos entre los hombres que la hicieron posible (Zacarías, 2009).

\section{Un acercamiento conceptual a la identidad}

La ciudad, se ha constituido históricamente como un archivo cultural en el que se guardan presencialmente las sucesivas operaciones significativas que determinaban su realidad espacial y formal. La existencia de la arquitectura ha estado siempre acompañada por la del hombre, evidenciando su marcado carácter social, es por ello que constituye un factor esencial como reflejo y síntesis de la identidad de los pueblos y su devenir histórico.

Si bien reviste importancia la presencia del componente social en el tema de la identidad, se hace preciso destacar la significación del entorno físico, ya que es lo primero que se percibe en cada ambiente y depende de la significación de este, que los entes sociales logren un sentido de pertenencia para con él. Por ello, se considera la identidad cultural a partir de entender la producción de respuestas del sujeto social, "como heredero y transmisor, actor y autor de su cultura, que este realiza en un contexto geohistórico dado (García, 2002, p. 109).

La arquitectura vista como fenómeno complejo exige la necesidad de profundizar en el análisis de los problemas sociales y del comportamiento sociocultural que influye en el uso del espacio urbano y arquitectónico de forma que valorice el papel cultural de la arquitectura ya que constituye una realidad histórica y no puede aislarse de los grandes acontecimientos de una época, ni del progreso técnico, ni de la vida cultural. Ella no sólo comprende las huellas de la historia sino también los procesos evolutivos de cada núcleo. Esto permite entender la identidad cultural como concepto dialéctico que se enriquece con las aportaciones de los hombres en cada momento histórico y que no concluye ni siquiera con la muerte, pues contrario a lo que se piensa, la identidad es lo que queda, lo que da vida y significado a las practicas, los sucesos, las costumbres, en fin lo que se trasmite como algo inacabado.

Los aportes de la Doctora Eliana Cárdenas (1998) a las dimensiones de la identidad cultural son un referente obligado. En la dimensión sociopolitica y geográfica se otorga importancia al espacio físico con su historia vinculada a un paisaje que interactúa con el hombre. El asentamiento geográfico definitivo de una ciudad está condicionado por múltiples factores que influyen en la forma resultante que la define. Las características geográficas del paisaje condicionarán el desarrollo de una ciudad y definirán rasgos morfotipológicos que son apreciables en los núcleos urbanos y unido a ello otros factores como los ya mencionados, influyen y determinan en la formación y consolidación de un asentamiento.

La dimensión socioeconómica reconoce el valor de la arquitectura y los espacios urbanos como reflejo de la estructura social. En este sentido se puede afirmar que desde la concepción de una ciudad, se generan espacios de mayor o menor jerarquía. La significación de estos espacios no sólo se distingue a nivel urbano, sino además por la arquitectura que los compone. La identidad considera además una dimensión sicosocial que abarca las maneras de pensar y de actuar de los diferentes 
grupos sociales; así como los procesos de percepción que conforman los imaginarios colectivos que desempeñan un papel esencial en la construcción, reafirmación y difusión de los valores identitarios. El factor social constituye el componente principal en el aseguramiento de la memoria colectiva y la identidad cultural de los pueblos.

Finalmente debe considerarse la dimensión antropológico-cultural con las diferentes influencias culturales que definen las prácticas culturales y la dimensión estético-formal que condiciona los criterios para valorar los objetos culturales, los modos de usarlos, representarlos y asignarle valores significativos. La continuidad formal y la reinterpretación de valores auténticos, constituyen los verdaderos aportes de la arquitectura contemporánea.

Las representaciones sociales tienen de base un fondo cultural acumulado por la sociedad, que forman la identidad que "es la expresión (o conjunto de expresiones) de los valores esenciales reconocidos por una comunidad. Estos pueden referirse a la historia y las vivencias comunes, resultado de las interrelaciones múltiples de carácter dialéctico entre las costumbres, las tradiciones y las transformaciones generadas de acuerdo con los cambios en las formas de vida en cada etapa histórica" (Alfonso, 2014, p. 27).

Para Horacio Gnemmi (1997, p. 183) "El conocer antecede el conservar, en tal sentido a la búsqueda del conocimiento se le puede considerar como la primera respuesta de una actitud de conservación. En el caso específico de la conservación del patrimonio arquitectónico, conocer implica investigar, indagar para que de dicha búsqueda nazca el conocimiento que luego reclame de la conservación respuestas concretas". Los centros históricos son los sitios donde se puede realizar la apropiación de una imagen llena de recuerdos y significados, ya que ella "representa la memoria colectiva de la ciudad construida sobre esos elementos paisajísticos heredados" (Camallonga, 2013, p. 118). Los cambios producidos en los espacios urbanos a través de los siglos y producto de la modificación de las formas de vida, de la cultura, las transformaciones productivas y económicas, provocan una serie de modificaciones, algunas veces drásticas, en los centros históricos. Como plantea Delgado (2015, p. 9), "el patrimonio urbano que no se hace consciente en el imaginario, no se encuentra protegido, es un patrimonio invisible, un patrimonio en riesgo".

Mucho se ha discutido en el ámbito académico sobre la necesaria relación entre el turismo y las ciudades patrimoniales, así como sobre los aspectos positivos y negativos derivados de ella, pero se coincide en que:

Si bien es cierto que en el binomio turismo-ciudad el primero apunta casi siempre hacia la distorsión $y / 0$ cambio de la segunda, pensamos que una adecuada planificación y dirección del turismo urbano o "de ciudad" (entendido éste como aquel que presenta a la ciudad en toda su magnitud como principal producto turístico) puede contribuir a estimular la protección de las ciudades históricas, la arquitectura tradicional, los monumentos y otras manifestaciones, lo que consolida valores culturales en la conciencia de los pueblos y fortalece el orgullo nacional. Visto de esta forma, el turismo se convertiría en el instrumento idóneo para revalorizar culturas y horadar en sus particularidades, logrando que sean conocidas por la humanidad. (Gómez, 2002, p. 127).

\section{Turismo urbano, usos y apropiaciones del patrimonio}

La preocupación científico-social por el desarrollo equilibrado de la actividad turística no es nueva, pero adolece de las mismas carencias que el tratamiento del turismo en su dimensión más global, es decir, la escasa atención y preocupación desde el ámbito de la investigación, hasta fechas relativamente recientes. Numerosos investigadores han abordado desde los más diversos enfoques la problemática del turismo en los centros históricos. La aproximación al estado de las investigaciones precedentes pone de manifiesto, ante todo, la existencia de un bagaje de experiencias en cuanto a técnicas e instrumentos para la planificación y gestión del turismo, pero la necesidad del desarrollo turístico obliga a la elaboración de metodologías o procedimientos integradores, con un alcance más amplio.

Si bien el turismo para el área geográfica del Caribe ha priorizado los destinos de sol y playa por la riqueza inigualable de sus atractivos naturales, no es menos cierto que muchas de sus ciudades poseen también un valioso patrimonio urbano-arquitectónico. De allí que las zonas de altos valores patrimoniales de una ciudad entendidas como núcleos monumentales en los que puede desarrollarse el turismo urbano sostenible, concentran la esencia de la identidad de un sitio, pues perduran en sus espacios valores simbólicos, arquitectónicos y urbanos (Yeras, 2015). Las enormes expectativas puestas en el turismo como factor de desarrollo, obligan a plantear con rigor los fundamentos de una planificación y gestión, en primer lugar, acorde con los recursos culturales, pues la conservación y preservación de estos 
constituye un proceso complejo y singular que requiere de un adecuado manejo desde una óptica multidisciplinaria y metodológica y en segundo lugar porque son esos mismos recursos la garantía de futuro del sector cuando se trata de sitios patrimoniales y de su competitividad en el escenario internacional.

Es por ello que entender el término patrimonio y su relación con el turismo, es necesario a los efectos del desarrollo integral de las ciudades. A partir de la segunda mitad del siglo XX se produce el "boom" turístico internacional y los gobiernos empiezan a considerar el turismo como un sector estratégico para su política económica. En la actualidad el fenómeno turístico mueve millones de personas en el mundo y tiene repercusiones de muy diversa índole. El turismo adquiere en ese nuevo escenario un protagonismo total, al que se suma la prioridad dada, por parte de muchos territorios, que lo ven como elemento de dinamización económica y social. Aparejado a este fenómeno surge la necesidad de adaptarse a las nuevas condiciones de competencia entre los destinos, así como a los rápidos y profundos cambios de las motivaciones, preferencias y hábitos de los consumidores y por último al marco institucional y tecnológico que debe sustentarlo.

El crecimiento competitivo de los destinos turísticos debe basarse en los principios de especialización y diferenciación a través de procesos de planificación estratégica que se adapten a la fase de desarrollo en la que se encuentre cada destino, pues las necesidades son distintas según se trate de destinos emergentes, en crecimiento o maduros. Es aquí donde juega un papel esencial el determinar aquello que los distingue y los diferencia de la competencia, lo que se traduce en buscar las ventajas comparativas del destino.

A partir de la década de 1990 se han propuesto diferentes modelos teóricos para el análisis de la competitividad de los destinos turísticos, la que en el caso de los núcleos monumentales pasa inevitablemente por la preservación de la identidad cultural del destino. No es un secreto para nadie que muchos países han optado por desarrollarse como destinos turísticos, en ello ha incidido el avance en las tecnologías de la información y la comunicación que acorta distancias entre territorios, así como las nuevas motivaciones de los turistas para viajar, que tienden a alejarse del turismo tradicional en beneficio de un turismo basado en el descubrimiento de nuevas experiencias, lo cual ha provocado que se eleve el número de destinos turísticos (Flores \& Barroso, 2009).
El término destino turístico ha sido abordado ampliamente en la literatura científica sobre el tema, a juicio de la autora el concepto más completo es el dado por Valls $(1998$, p. 4) que lo define como un

\begin{abstract}
espacio geográfico determinado, con rasgos propios de clima, raices, infraestructuras y servicios, y con cierta capacidad administrativa para desarrollar instrumentos comunes de planificación, que adquiere centralidad atrayendo a turistas mediante productos perfectamente estructurados y adaptados a las satisfacciones buscadas, gracias a la puesta en valor y ordenación de los atractivos disponibles, dotado de una marca y que se comercializa teniendo en cuenta su carácter integral.
\end{abstract}

En este sentido cualquier plan estratégico de largo plazo debe tener como objetivos el mantenimiento armónico del equilibrio dinámico hombre-territorio y la revalorización del emplazamiento basado en las raíces propias que mejoren la calidad de la experiencia turística.

La interrelación turismo-patrimonio está fundamentada en que no es posible diseñar ni realizar una cultura para el turismo, tampoco es posible desarrollar o consolidar el mismo sin que esté presente la cultura nacional y local como parte misma del atractivo turístico. Algunos estudiosos del tema del turismo urbano, Köster y Serrano (2005, p. 2), plantean que "no cabe ninguna duda que el turismo urbano es un fenómeno emergente que está reconfigurando en los últimos años los flujos turísticos (...). La ciudad deviene así en un producto atractivo y se configura como elemento determinante en la configuración de la demanda turística".

En los centros históricos y zonas con valor patrimonial, influyen hoy en día situaciones complejas derivadas de la manera de usar el espacio. Aplicar categorías de intervención en los bienes patrimoniales con el fin de dotarlos de funciones contemporáneas es una alternativa posible y viable. El reuso/reciclaje/refuncionalización es la acción que se ejerce sobre un edificio y/o conjunto urbano implicando un cambio de uso en su función original, pero rescatando los valores que se conserven. Como plantea Alfonso (2014, p. 36) los cambios de uso durante la rehabilitación están asociados entre otras razones a las nuevas funciones que han generado los estilos de vida contemporáneos, pero "debe tenerse en cuenta la vocación funcional del bien inmueble, de modo que la nueva función que se le asigne sea compatible con las características físicas del edificio y del contexto, y favorezca los procesos de conservación de sus valores culturales". 
El nuevo uso no implica desconocer la tipología, la vocación e imagen primarias, por tanto deben preservarse no solo los valores que contiene el bien sino igualmente su esencia cultural. La participación ciudadana es aquí fundamental para generar procesos de identidad y apropiación, reafirmándose así valores locales, que son a su vez de gran importancia para la percepción y apropiación del patrimonio urbanístico, cultural y ambiental y para generar un desarrollo sostenible acorde con las características propias. Cuando se selecciona un bien patrimonial "el mensaje es el punto inicial para determinar la individualidad y, más allá, la originalidad, para que la instalación tenga su propia identidad, con el fin de que sea recordada por quien la visita y se condicione determinado prestigio" (Rigol \& Rojas, 2012, p. 540).

\section{Camagüey, pasado presente y futuro: Retos en la permanencia de su memoria}

Camagüey, ciudad única por su origen, transformación e historia, es el resultado de 500 años de desarrollo que han dejado huellas en su estructura física (Figuras 1 y 2).

Figura 1. Grabado del Siglo XVIII

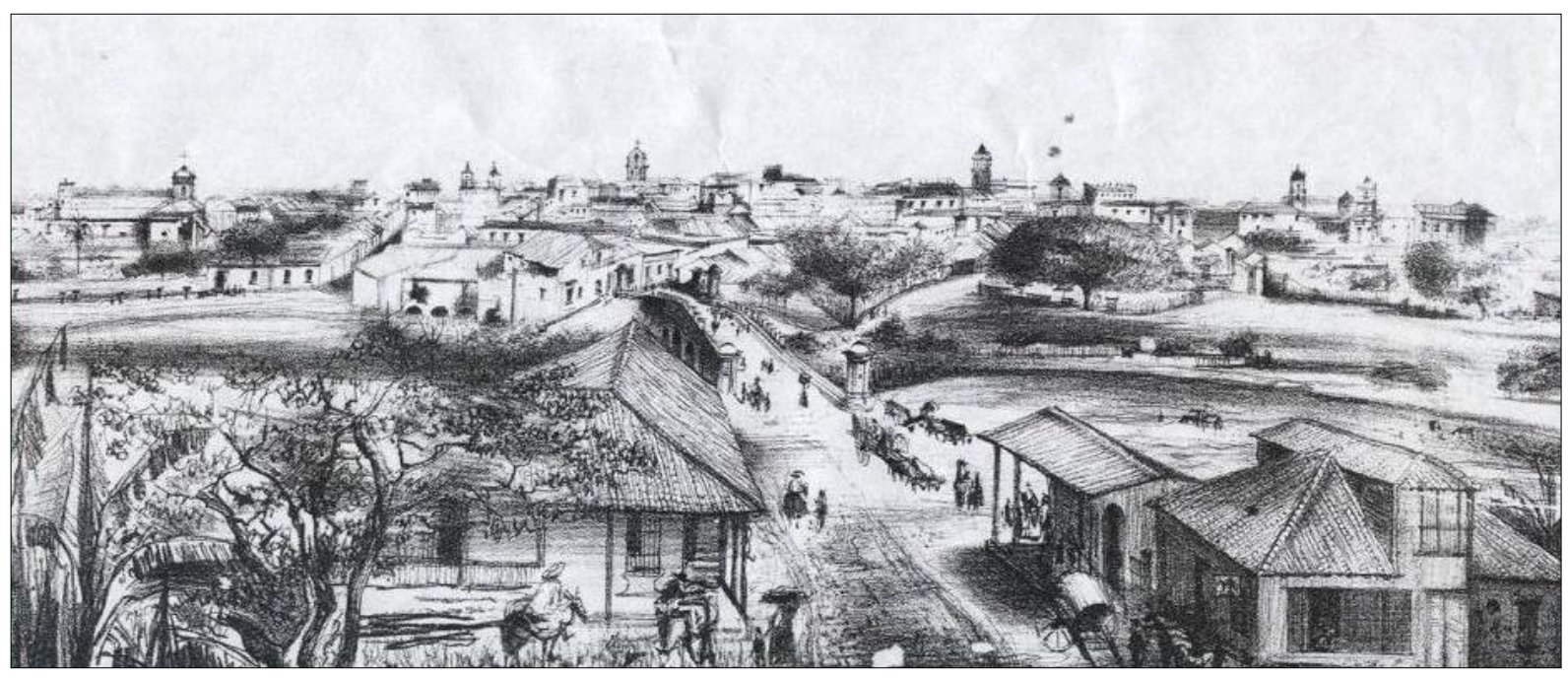

Fuente: Yeras, M. T. C. (2005). Lenguaje de poderes en la estructura física de Santa María del Puerto del Príncipe. Siglos XVI-XVIII. Disertación doctoral no publicada. Universidad Pablo de Olavide, Sevilla, España.

Figura 2. Vista aérea de la ciudad de Camagüey

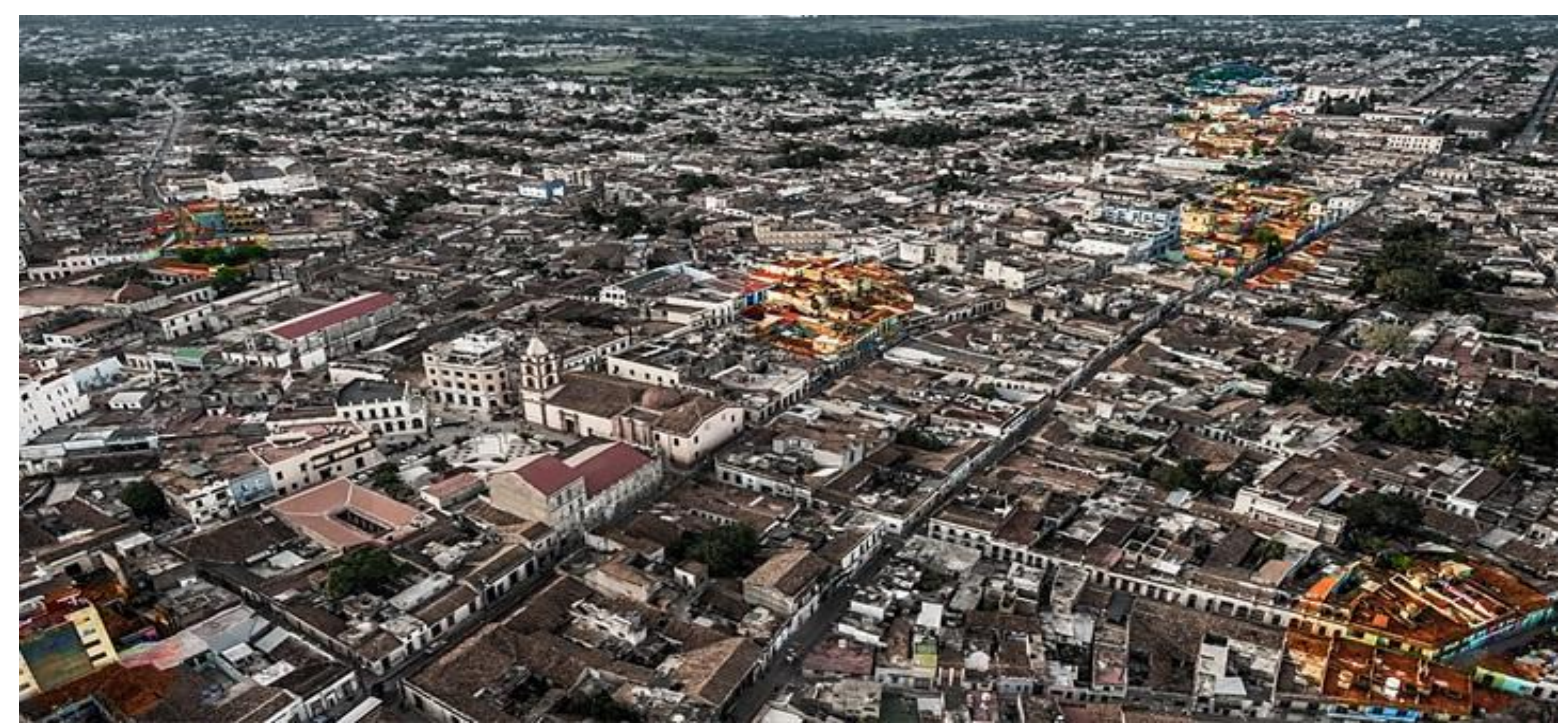

Fuente: Fondo fotográfico del Centro de Estudios de Conservación y Desarrollo de las Construcciones (CECODEC). Universidad de Camagüey. 
Etapas de fuertes cambios estructurales provocaron procesos de densificación de la trama existente, mientras que las etapas de auge económico generaron grandes expansiones urbanas. En su centro geométrico se localiza la ciudad tradicional, espacio de altos valores arquitectónicos, urbanos, culturales y patrimoniales que la población reconoce como su espacio de interacción social. Como resultado de éste proceso, en el que se construye también la imagen de la ciudad simbólica, se obtiene un trazado que respeta en su punto central, o sea, la plaza mayor, lo establecido como modelo para las nuevas fundaciones, y rompe con ello en la configuración del resto de la trama urbana que resulta un tejido irregular en el que si bien no está presente la linealidad de sus calles y manzanas, subyace un trazado que da respuesta a las relaciones funcionales principales.

Según el Manual para Inventarios de Bienes Culturales Muebles del Ministerio de Cultura de Colombia (2005, p. 37) "en el mismo instante en que se fija la atención sobre una expresión de la cultura, hay valoración." Camagüey es ciudad de iglesias, tinajones, leyendas y tradiciones; no hay dudas de sus elementos identitarios. Basta mencionar el trazado urbano, con su sistema de calles y callejones, que desembocan en plazas y plazuelas, en las que se encuentran casi siempre iglesias como hitos singulares de carácter monumental que sirven para orientarse en su irregular trama. El marcado ambiente vecinal de los barrios que hasta hoy prevalece en su centro histórico, la homogeneidad en la arquitectura de conjuntos tan significativos como los del Carmen y San Juan de Dios, así como la armónica expresión que logran los más variados estilos eclécticos y coloniales en una imagen urbana cautivadora, constituyen elementos excepcionales que le han conferido a Camagüey su condición de Patrimonio Cultural de la Humanidad, amparado en los criterios IV y V (UNESCO, 2008): por ser ejemplo excepcional de un conjunto arquitectónico que ilustra un período histórico significativo y por constituir un ejemplo excepcional de un hábitat humano tradicional, representativo de una cultura y de su interacción con el medio ambiente, respectivamente (Figuras 3 y 4 ).

La construcción simbólica de la ciudad permite considerar en una primera Etapa de Formación (1528-1692) una estructura que respondió a las condiciones del medio físico, a las relaciones funcionales principales y a los intereses de las clases con recursos económicos. Ello originó la regularidad y simplicidad del espacio principal convertido en centro de poder y la "arbitrariedad" en el resto de la trama al alejarse de dicho núcleo que, tanto a nivel urbano como arquitectónico, fue consecuencia espacial y formalmente del repertorio habitacional. Esto se manifestó a nivel urbano, por la falta de normativas en la concesión de solares para particulares dando como resultado la irregularidad de los lotes y manzanas y a nivel arquitectónico, por la expresión formal de las viviendas de los vecinos principales quienes expresaron en ellas su poderío económico.

Figuras 3 y 4. Plaza del Carmen, Camagüey (Izquierda). Casa del altillo en la Plaza de San Juan de Dios, Camaguey
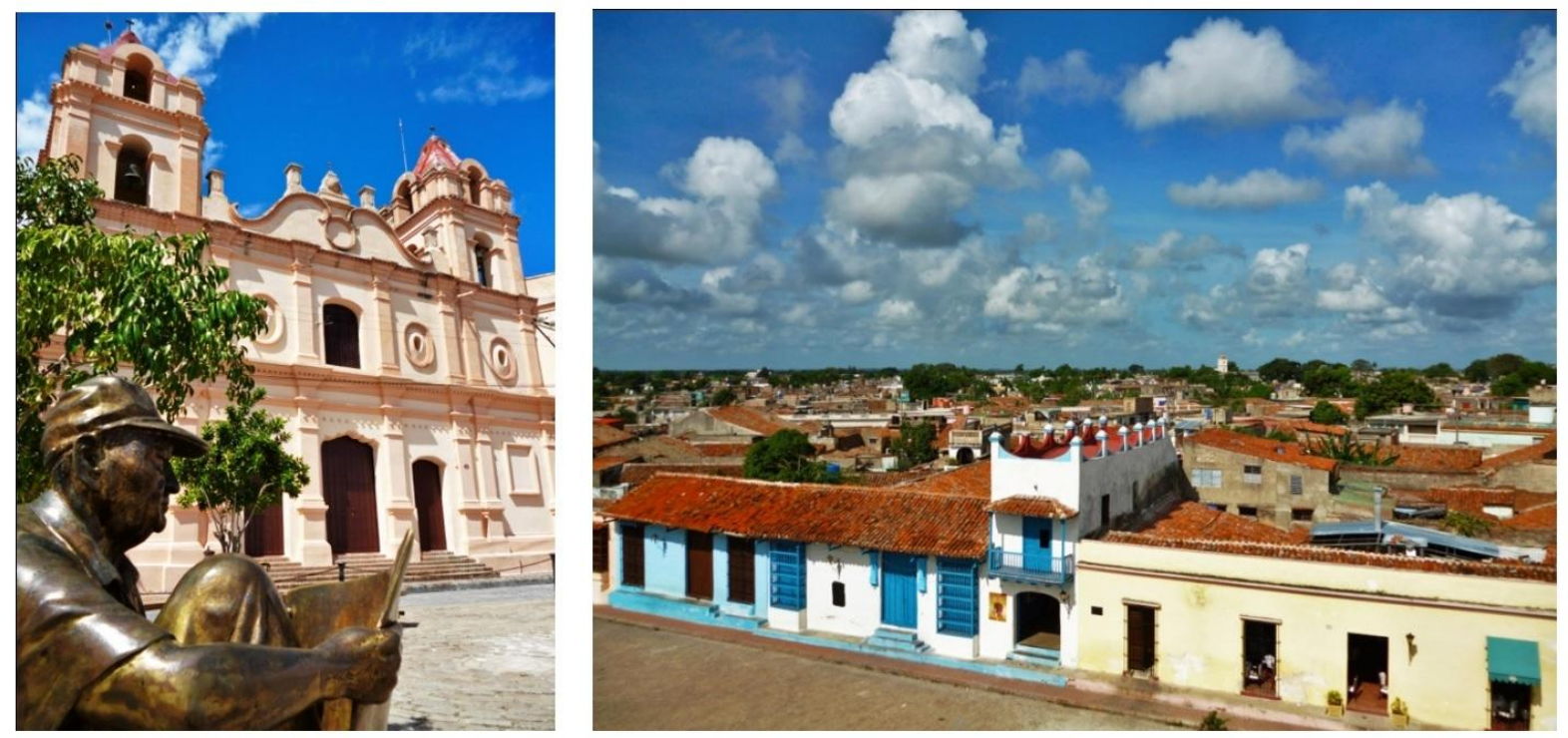

Fuente: Fondo fotográfico del Centro de Estudios de Conservación y Desarrollo de las Construcciones (CECODEC). Universidad de Camagüey. 
La segunda etapa de Desarrollo y Consolidación (1693-1800) marcada por el crecimiento poblacional y el auge económico de los principales vecinos fruto del contrabando y del fomento de sus haciendas; dio como resultado la estabilidad y el crecimiento del núcleo urbano, que no dejó de expresar, a nivel arquitectónico y urbano, la importancia del repertorio habitacional, pero que a ello se sumo la jerarquía del poder civil y religioso, manifestándose en las edificaciones que respondieron a esos fines.

La morfología urbana de la ciudad posee como tipología un modelo irregular. Se produjo un crecimiento por extensión marcado por la ubicación de las edificaciones del repertorio religioso y un reforzamiento de la centralidad de la ciudad. Ello fue posible por la presencia de los símbolos de poder como la iglesia, el cabildo y las viviendas de la élite principeña y de las acciones simbólicas, o sea, de los usos del espacio central para fiestas, procesiones, desfiles militares y demás actividades que garantizaron que los grupos sociales defendieran este espacio como "su" espacio vital.

$\mathrm{Su}$ ubicación mediterránea y en la confluencia de dos ríos, le permitió contar con fuentes de abasto de agua y terrenos fértiles y llanos que propiciaron su desarrollo económico, lo que estuvo respaldado por un crecimiento poblacional desde fines del XVII y durante el XVIII. El proceso de síntesis que se produce entre las características del hábitat, las costumbres y otros elementos de la cultura material y espiritual de pobladores autóctonos y conquistadores, fueron determinando su configuración espacial urbana y arquitectónica que aun puede verse reflejada en nuestros días, pero no basta que un sitio patrimonial sea oficialmente reconocido como tal, sino que debe garantizar su protección futura y mecanismos que le permitan una adecuada adaptación ante los cambios socioeconómicos que acaecen en las ciudades patrimoniales.

Ante esta realidad la conservación del patrimonio debe partir del reconocimiento de sus valores que constituyen legado del pasado, del sentido de pertenencia sobre el mismo y del sentimiento de responsabilidad de protegerlo por la sociedad. El actual e inevitable desarrollo plantea nuevos desafíos a las ciudades, incluidas las patrimoniales y trae aparejado consecuencias que estamos lejos de comprender y de enfrentar. La concentración poblacional con la problemática añadida del tratamiento de las aguas, la eliminación de desechos, la propia escala de las urbanizaciones, la contaminación atmosférica por el flujo vehicular, o simplemente la contaminación sonora, la sobrecarga y excesiva explotación de los terrenos,
Usos y apropiaciones del patrimonio urbano VS identidad perdida o conservada

el mal manejo de las fuentes de energía renovables y no renovables; por solo mencionar algunos ejemplos, tienden a su vez a crear efectos irreversibles que afectan inevitablemente a nuestras ciudades y a su patrimonio cultural y lo ubican en el límite de su capacidad de sustentación. A ello se suma la dualidad de funciones como centro de ciudad y el compartir su uso de suelo con poblaciones diversas derivado de la coexistencia del espacio físico, urbano y turístico.

La explotación de los recursos naturales y la afectación al medio ambiente reportan en muchas ocasiones, no sólo su deterioro sino también su pérdida, sin posibilidad de restauración o reposición. Esto es particularmente nocivo en lo que concierne al patrimonio, tanto natural como cultural, pues es la base para el desarrollo y representa la historia de la vida y de la humanidad. Concientizar en la población, que quiere decir que las personas realicen un proceso de aprendizaje que las comprometa de forma integral, en el pensar, en el sentir y en el hacer, sobre la necesidad de minimizar los impactos negativos al medio ambiente; es una necesidad impostergable de la humanidad, no hacerlo compromete la vida del hombre.

\section{Conclusiones}

El espacio urbano aparece conformado por los hechos físicos o, lo que es igual, la arquitectura; pero las ciudades son en esencia un producto humano condicionado por factores económicos y sociales que van determinando su configuración y en la que también influyen un conjunto de circunstancias que las hacen únicas y de su tiempo. A su vez la arquitectura le otorga a la ciudad la capacidad de transmitir significados a partir de los usos y apropiaciones de sus espacios por el hombre, lo cual es decisivo para la conservación o pérdida de sus identidades. La conservación debe asegurar que el patrimonio de los pueblos forme parte de la historia viva de la ciudad y que pueda ser accesible a las generaciones presentes y futuras.

\section{Referencias bibliográficas}

Alfonso, A. (2014). Conservación del patrimonio cultural inmueble. Temas introductorios. La Habana, Cuba: Editorial. Editorial UH. Universitaria Félix Varela.

Boisier, S. (1999). Teorias y metáforas sobre desarrollo territorial. Santiago de Chile: Editorial de la ONU. 
Brandis, D. \& Del Río, I. (1998). La dialéctica turismo y medio ambiente de las ciudades históricas: una propuesta interpretativa. Ería, 47, pp. 229 240. Recuperado de http://www.unioviedo.es/reunido/index. $\mathrm{php} / \mathrm{RCG} /$ article/viewFile/1288/1207

Camallonga, J. S. (2013). Centros históricos: Análisis y perspectivas desde la Geografía. GeoGraphos, 4 (37), pp. 117-139. doi: 10.14198/GEOGRA2013.4.37

Castro, F. (2001). Masificación de la cultura contra cultura de masas. Palabras en el Consejo Nacional de la Unión Nacional de Escritores y Artistas de Cuba], La Habana, Cuba.

Cárdenas, E. (1998). Problemas de teoría de la arquitectura. Universidad de Guanajuato, México: Editorial Universitaria.

Colectivo de Autores (2011). Manual para Inventarios de Bienes Culturales Muebles del Ministerio de Cultura de Colombia. Quito: Ediecuatorial.

Chateloin, F. (2009). El patrimonio Cultural Urbano y el criterio de Centro Histórico. Caso de estudio: Ciudad de la Habana. Instituto Superior Politécnico José Antonio Echeverría. Facultad de Arquitectura. La Habana, Cuba: [s.n].

Delgado, A. J. A. (2015). La situación del patrimonio urbano en la periferia de la gran ciudad: patrimonio oficial versus patrimonio identitario. El caso de Carabanchel Alto (Madrid). Recuperado de https://upcommons.upc.edu/bitstream/h andle/2117/79072/47BCN Antequera A ntonio.pdf?sequence $=1$ \&isAllowed $=\mathrm{y}$

Flores, D. \& Barroso, M. (2009). Análisis de la competencia en la actividad turística. Oviedo: Septem ediciones.

García, M. (2002). Identidad cultural e investigación. Centro de Investigación y Desarrollo de la Cultura Cubana "Juan Marinello". La Habana: [s.n].

García, M. \& Baeza C. (2004). Modelo Teórico para la Identidad Cultural. Librería Santa Fé. Argentina. Recuperado de http://www.lsf.com.ar/libros/01/modeloteorico-para-la-identidad-cultural/

Galeano, E. (1975). Las venas abiertas de América Latina. La Habana, Cuba: Editorial Ciencias Sociales.

Gómez, O. (2002). Turismo y ciudad: una perspectiva sociológica. Universidad de Oriente, Santiago de Cuba: [s.n].

Gnemmi, H. (1997). Puntos de Vista sobre la conservación del patrimonio arquitectónico y urbano. In E.
ENDECOR (Ed.). Córdoba, Argentina: Editorial de textos universitarios.

Guanche, J. (1999). España en la savia de Cuba. La Habana, Cuba: Editorial de Ciencias Sociales.

Guerrero, R. M. (2012). Premisas y aportes de la teoría de las representaciones sociales a los estudios sociológicos. Recuperado de http://www.fesweb.org/uploads/files/modules/congress /10/grupos-trabajo/ponencias/845.pdf

Habas, J. \& Santamaría, E. (2001). Sobre espacio, distancia y hospitalidad. Revista Iberoamericana Astrágalo, 18, pp. 15-31.

Köster, P. R. \& Serrano, M. F. (2005). Una aproximación al turismo urbano. El valor de la ciudad empaquetada en el caso de Valencia. Recuperado de http://burgosciudad21.org/adftp/Una ap roximaci $\% \mathrm{C} 3 \% \mathrm{~B} 3 \mathrm{n}$ al turismo urbano. El valor de la ciudad empaquetada en el caso de Valencia.pdf

Lefebvre, H. (1972). Espacio y política: El derecho a la ciudad, II. Barcelona: Ediciones Península.

Moro, A. P. (1985). Metodología de la investigación histórica. La Habana, Cuba: Editorial Pueblo y Educación.

Moya, N. \& Brito, J. M. (2001). Masividad de la cultura vs cultura de masas: a propósito de una estrategia cultural. Cuba Socialista, (20), pp. 36-45.

Muntañola, J. (2000). Sobre la búsqueda del núcleo de la investigación en arquitectura. España. Recuperado de www.arquitectonics.com.

Pupo, R. (2007). El ensayo como búsqueda y creación (Hacia una aprehensión compleja) (Monografia). Universidad Popular de la Chontalpa, Tabasco, México.

Racionero, L. (1986). Sistema de ciudades y ordenación del territorio. Madrid: Alianza Editorial.

Rigol, I. \& Rojas, Á. (2012). Conservación patrimonial: teoría y crítica. La Habana, Cuba: UH Editorial.

Rodríguez, A. C. (2009). Hacia una antropología urbana en Cuba. La Habana, Cuba: Fundación Fernando Ortiz.

Rueda, S. \& Naredo, J. M. (1996). La ciudad sostenible: Resumen y conclusiones. In Primer catálogo español de buenas prácticas. Madrid: Centro de Publicaciones Secretaría General Técnica. Ministerio de Obras Públicas, Transporte y Medio Ambiente.

Stevens, G. (1998). The Favoured circle: the social foundations of arquitectural distintions. Cambridge: Mits Press.

UNESCO (2008). Inscripción del Centro Histórico de 
Camagüey (C1270), Cuba, en la Lista del Patrimonio Mundial. (WHC/ 74210.1/NS/mgl/176). Paris: UNESCO.

Valls, J. F. (1998). Cambio de concepto en la gestión turística del municipio. Estudios de Gestión Turística. 7, pp. 3-7.

Van Hooff, H. (2006) Director de la Oficina de la UNESCO en La Habana y de la Oficina Regional de Cultura, comentarios con motivo de evaluar el Modelo de Gestión Integral de La Habana Vieja.

Valcárcel, J. O., (2000). Los horizontes de la Geografía. Teoría de la Geografía. Barcelona: Editorial Ariel S.A.

Yeras, M. T. C. (2005). Lenguaje de poderes en la estructura física de Santa María del Puerto del Principe. Siglos XVI-XVIII (Tesis Doctoral). Universidad Pablo de Olavide, Sevilla, España.

Yeras, M. T. C. (2015). La identidad cultural en el centro de la gestión turística de los núcleos monumentales. In Gómez, L. \& Niglio (Eds.), O., Conservación de centros históricos en Cuba (pp. 657- 675). Roma: Editorial edA Esempidi Architettura, Aracne Editrice.

Yeras, M. T. C. (2016). La arquitectura vernácula como importante manifestación de la cultura. Arquitecturas del Sur. 47 (33), pp. 62-73.

Yeras, M. T. C. \& Sóñora, B. (2013). Procedimiento para la promoción turística de las ciudades patrimonio de la bumanidad. In III Congreso Iberoamericano y XI Jornada de Técnicas de Reparación y Conservación del Patrimonio. La Plata, Argentina: Laboratorio de Entrenamiento Multidisciplinario para la Investigación Tecnológica (LEMIT). Recuperado de http://digital.cic.gba.gob.ar/handle/12345 $\underline{6789 / 333}$

Zacarías, P. (2009). La restauración arquitectónica: aproximación a la teoría. In VV. AA., Entornos sustentables. Investigaciones de posgrado. Xalapa: Editorial de la Universidad Veracruzana, pp. 91-98.

\section{Cómo citar este artículo}

Yeras, M. B. C.. (2018). Usos y apropiaciones del patrimonio urbano VS identidad perdida o conservada. PatryTer, (1), 1, pp. 22-33.

DOI: https://doi.org/10.26512/patryter.v1i1.7108 